\title{
Opinions and Views on the Reflection of the Interaction in the Teacher-Cadet Position
}

\author{
Bashirova Gulshan Ismayil ${ }^{1}$ \\ ${ }^{1}$ Department of the Azerbaijan Higher Military School named after Heydar Aliyev, Baku, Azerbaijan \\ Correspondence: Bashirova Gulshan Ismayil, Department of the Azerbaijan Higher Military School named after \\ Heydar Aliyev, Baku, Azerbaijan.
}

Received: October 28, 2021

Accepted: January 24, 2022

Online Published: January 28, 2022

doi:10.5539/mas.v16n1p49

URL: https://doi.org/10.5539/mas.v16n1p49

\begin{abstract}
Opinions and views on the reflection of the interaction in the teacher-practitioner position are analysed and interpreted in detail. It is noted that the acquisition of excellent knowledge and skills by future officers and the level of professionalism that meets modern requirements also depends on the teacher-intern relationship. The article suggests three styles of activity: 1) preventive style (the teacher actively influences and follows the development of the student's personality); 2) supportive style (the teacher adapts to the development of the trainee's personality - supports the best in the development of his personality); 3) situational style (teacher only has a situational impact on the development of the trainee and his personality). It is emphasized that the "personality" approach is now a strategic task of pedagogical technology in the process of military education. The factor that creates the system in this approach is the unique personality of the student. Based on psychological research, the position of the individual began to be defined by philosophers as a structural-personality structure that reflects the nature of the relationship between the individual and society: The position of the individual is a system of relations of the individual to society, other people and himself, stable, intuitive.
\end{abstract}

Keywords: position, personality, extracurricular activities, potential, communication

\section{Introduction}

Our national leader Heydar Aliyev has always attached special importance to the issue of army building as a guarantor of our independence: "Today we proudly celebrate the existence of the National Army of the independent Republic of Azerbaijan. This is a great national success of the Azerbaijani people "(Aliyev, $\mathrm{n} / \mathrm{a}$ ).

Under the leadership of our Supreme Commander-in-Chief Ilham Aliyev, our occupied lands were liberated because of the 44-day victory war. After the war, some revanchist forces continued their insidious positions and provoked. The training of fighters remains on the agenda. The relevance of the topic of extracurricular activities is clearly understood.

There are great opportunities for extracurricular activities. In addition to revealing the development potential of teacher-intern relations, the role of extracurricular activities in the formation of professional orientation, professional and socially important qualities of the individual, self-determination, subjectivity, responsibility, activity, and initiative is great. The potential of teacher-trainee relations, the role of extracurricular activities in the formation of professional orientation, professional and socially important qualities of the individual, self-determination in life, subjectivity, responsibility, activity, and initiative are great.

\section{Research Topic}

Extracurricular activities have a special role in increasing the reliability and sincerity of teacher-intern relations in military universities. Extracurricular activities are any activities carried out by cadets in a military school, but not limited to the curriculum, aimed at the formation and development of socially and professionally important qualities that contribute to the growth and deepening of life experience.

Analyzing the process of development of teacher-practical relations in extracurricular activities, we note the following potentials of this activity: information, communication, organization, demonstration, integration. These potentials help to successfully address the issues of special vocational education in the training of military 
specialists. The main result is that extracurricular activities are less likely to be regulated, creative, and to implement, teach, guide, and integrate the goal-action-result-reflection algorithm.

The integration potential of extracurricular activities is to create conditions for mutual interaction in the content of various subjects, teaching, and extracurricular activities, training, and military service elements, in which process the teacher-trainee relationship rises to a higher level (Note 1) (Bashirova, 2018a, 2018b, 2020a, 2020b). Integration (lat. Integration - restoration, completion) - a combination of any parts into a single whole; it is the unity of different elements and the process that leads to this situation (Bashirova, 2019a). Integration is the process of bringing parts together around common goals, consciously combining different elements and resources to achieve those goals. Integration in the teaching process implies two types of completeness: horizontal (close interdisciplinary connection, unity of knowledge and skills) and vertical (inheritance at different levels of education) (Note 2) (Bashirova, 2019b, 2020c). For this reason, the general theoretical and special knowledge of cadets, theoretical knowledge that ensures the mastery of the principles and physical foundations of communication, technique and weapons are based on practical skills, combat, moral and psychological training (Bashirova, 2018c).

Modern training for the army also depends to some extent on the establishment of relations between teachers and cadets in accordance with the necessary pedagogical requirements. The issue of "identity position" is important in this chain of relations.

As is well known, the term "identity position" was coined by Adler. In the foreign psychological and sociological literature, this concept is accepted as a social direction. Lingard considers the "position" because of the process of socialization and at the same time an internal need to act in a desirable way under certain conditions. Ananyev (1968) defines "personality position" as a complex system of relations. In this situation, the "most important" relationship that shapes the character is the relationship of society with ideology, labor, other people, and himself. Personality interactions express the position of personality. Since personality is a systemic being in the interaction of personality, the position in the interaction of personality is also systematic. Personality-oriented responsibilities include:

1) a special type of attitude of the educator towards himself, based on the principles of self-analysis, self-criticism, and freedom, aimed at clear education and success;

2) a special type of relationship with others based on the principles of cooperation, joint creativity, mutual care, mutual respect, and mutual understanding, resulting from productive interaction in solving problems;

3) a special type of approach to pedagogical activity, which provides the difficulty, freedom, and originality of perception.

The social and socio-psychological nature of the personality position is different. In the modern philosophical, psychological, and pedagogical literature, there are two main approaches to understanding the nature of the position: sociological - in this case, the position is perceived as a condition of self-expression and socio-psychological - in this case, the position is perceived as a stable component.

Many teachers have also analyzed the concept of "personality position". For example, an individual's position as an internal conditional tendency to behave is considered a criterion of politeness. In this case, the position determines the formation of personality, ie the sum of personality traits and qualities. Ten socio-psychological features that characterize the style of pedagogical management are necessary: love for the student, pedagogical optimism, recognition of the student's personality, persistent approach to pedagogical work, demanding, patience, perseverance, responsibility, objectivity, vitality.

\section{3. "Teacher and Trainee" System of Relations}

Formalism and cooperation in the organization of the pedagogical process should be characterized by the interrelation of factors: students have a sense of psychological closeness to teachers, attention is paid to a person of high morals and self-confidence, no authoritarian forms of influence, and more appeal to internal content. More than the outward manifestation of character. Behavior leads to tendency, refers to the "intuitive" cause of a behavior. Yadav developed a theory of personality tendencies.

The concept of communicative position is also used in pedagogical literature. As we know, the position is always a reaction, from the inside to the outside, the attitude of society to the individual, to the particular in general. The position that emerges as a reaction and attitude characterize the attitude and behavior (action) that reflects the concept of "position". 
A position is an attitude toward any action or issue that determines the nature of a point of view, action, or behavior. Another definition states: "Position is a system of stable relationships that is reflected in a person's behavior and actions in accordance with certain aspects of reality." As for the teacher-practitioner relationship, there are different situations. Based on this, Yershov distinguishes three positions: "top addition", "bottom addition", "and close attachment". Dobrovic adds a fourth to these three positions - "not to participate." Ukhtomsky calls two positions: "similar" and "interlocutor". A "similar" position is when a teacher or student can only see themselves in the people they are talking to. The "interlocutor" position manifests itself in standing, seeing, and understanding the person in front of him or her, eliminating the superiority of the teacher's or student's own personality in communication.

Kan-Kalik identifies and characterizes several erroneous positions in professional behavior: "Skating" (Teacher's superiority over students), "Wall of China" (obstacle to mutual understanding between teacher and student), "Person who finds a place" (teacher working with the teacher) ignorance) class), "Friend" (a teacher who sacrifices business relationships for friendship), "Hamlet" (a teacher who is insecure, hesitant), "Deaf" (a teacher who only sees and hears himself in the classroom), "I" (teacher's activity) replaces with its own activity), etc., (Kan-Kalik, 1987).

The teacher's position in the field of communication may also reflect a direction determined by the age and psychological characteristics of the students. In this case, the following responsibilities of the tutor differ depending on how such conditions are met: organizer, leader, and consultant. If we talk about the military school, it means the transition from an external to an internal position in relation to the cadets; is a decrease in the share of direct impact on cadets and an increase in indirect impact; transfer of part of management functions to cadet self-government collective bodies; is to begin to have a high level of influence on the inner world of each student There is no doubt that all the positions we have mentioned and analyzed can be applied to teacher-practitioner interaction. However, during our research, basic conceptual approaches to teacher-trainee interaction were developed. The most important of these and their features are:

\subsection{Personality-Action Approach to Position}

According to Ananyev (1968), the position, as a subjective and action side of the status of the individual, reflects the complex system of relations of the individual, the direction and motives that guide his activity, the goals and values of this activity. In terms of the action approach, a position is defined as a person's relationship to an object. Positions refer to the evaluation of a particular object. In the sense of assessment, it is necessary to understand a person's positive or negative attitude towards any object, any "significant concern" associated with this object. "Positions lead to the acceptance or rejection of a particular object. This is reflected in the more or less constant attitude of man to that object" (F. Friedrich) (Vygotsky, 1984).

Such a position is an expression of a person's activity and his manifestation in action. For example, this is a manifestation of personality in the expert model, which also includes the following elements:

- types and functions of professional activity;

- $\quad$ structure of professional activity;

- professionally important personality traits;

- typical mistakes and difficulties;

- $\quad$ areas of activity.

Thus, the specialist model consists of a model of activity and a model of personality: 1) subjectivity (the active role of the person performing the activity and participating in the communication); 2) competence (optimal correspondence of purposefulness of the subject with the efficiency of its activity - unity of theory and practice, the readiness of the person to carry out the professional activity); 3) communicativeness, sociability; 4) reflexivity (self-awareness, self-attitude, self-reflection, how I am in reality, how someone sees me, how someone imagines me).

\subsection{Progressive and Reactionary Pedagogical Position}

The progressive position ensures the real, active, and creative participation of each trainee in the joint activity. Such a position is directed against the emergence of consumer technology in the student due to the reproductive nature of the transmission of experience. 


\section{3 "Leading-Conducting" Type of Position}

The position of the learners (conducted, active, employee, presenter) depends on the position of the teacher ("direct leadership - implementation", "equal rights", "secondary leadership - free action"). Thus, in pedagogical communication, the influence is not eliminated, on the contrary, it remains, but the one-way influence is replaced by two-way influence.

Scholars usually focus on the interaction of teachers and students from one status to another (lead-led, equality, partnership, led-led). Subject-object interaction has a complex internal structure and is doubly reflexive. The division of living activity into two interacting subjects leads to the fact that both parties act as both objects and subjects of activity. First, the teacher as a subject influences the cadet and creates a certain reaction in it, and then the trainee himself influences the teacher, in which case the teacher himself stands as a subject, conditions his actions, and reacts to the cadet's actions in a certain way. In each pedagogical situation, the teacher acts as both a subject and an object. It should be noted that the role of the object is also important for the teacher. Allows the trainee to understand, take into account his individual characteristics, to provide feedback. Pedagogical interactions are valuable only when teachers and students have subject-object relationships. Both sides are active in pedagogical interaction, so in fact, they rise to the level of subject-subject relations. Each subject of the pedagogical process feels the influence and affects itself. Because of the objective implementation of complex interactions, an internal mechanism of cognitive development emerges.

\subsection{Subjective Position}

As Slastenin (1998) writes, it is more expedient to accept subjectivity not as an important feature of human existence, but as a feature of the personality of the future specialist. The study of subjectivity is possible through the analysis of the position of the individual in the educational process. It has a different composition and varies in the range of object-subject position. The establishment of the latter, with the "teacher-trainee" communication provided by the appropriate educational organization, will contribute to the development of the subjectivity of the personality, its actualization in other areas of the life of the trainee.

The subjective position is a complex whole system, structurally uniting all components and means of interaction between them. Its blocks consist of motivation-valuable, relational, regulatory activity. By studying the phenomenon of the subjectivity of the cadet, we conclude that its study is possible only through the concept of "personality position". In general, the subjective position can be considered as a position of professional development of the individual and a systematic relationship of internal psychological elements that allow a person to interact in a certain way with the external and internal environment (Filatov, 1999).

The main condition for the development of the subjective position of the student is the compatibility and complementarity of external ideological influences with the internal potential of the individual. Ideally, the system of pedagogical requirements does not hinder the student's ability to search for ways of life and professional development, but rather stimulates his activity, selectivity, creative goals (Zuckerman, 1996; Babansky, 1982).

Speaking of the professionalism of the service member, we must emphasize that he acts as both a base and a key vector, determining the outcome and nature of communication. Features of the service member's position, such as humanism, socio-value orientation, psychological and pedagogical competence, service ethics, ensure his success, allow him to overcome the contradictions that arise during the implementation of the principle of unified leadership in subject-object relations. In this context, it is necessary to distinguish between "authoritarian", "liberal-privileged" and "true collectivist" pedagogical positions. These positions reflect the teacher's various goals (directions) aimed at the cadet (active-positive, passive-positive, passive-negative, and active-negative).

The social position of the teacher is of exceptional importance in the teacher-trainee relationship. This position can be divided into three different levels: 1 ) focus on the type of personality (the teacher approaches his goals in terms of the broad social requirements for the type of personality that currently dominates); 2) To have a limited understanding of the social functions of their activities (inculcate behavioral skills and impart knowledge); 3 ) based on the function of the activity (the type of teacher known for his commitment to the daily, traditional workflow and his disbelief in everything that goes beyond the events of the day).

Consideration of the direction of personality development depends on how it takes into account its recent development (which the trainee can perform only with the help of the teacher) and the actual direction of development (based on the personal development of the trainee without the teacher's help) (Best practices, 2019). There are three positions: a) optimal consideration of the immediate and topical areas of personality development 
in the learning process; b) the main focus in the learning process is on the immediate field of development and the lack of adequate connection with the actual development zone; c) the choice of position according to the role of the teacher in the development of the cadet's personality.

In addition to the lessons conducted in the classroom in accordance with the curriculum, extracurricular activities have great potential in optimizing the teacher-trainee relationship.

Russian pedagogue evaluating extracurricular activities as a joint activity of students and teachers, Burtseva (2005) states that this extracurricular activity, which is freer, purposefully ensures the development of the student's personality and the formation of his professionalism. It includes the following activities: students' activities in the field of individual research, as well as research, preparation of materials and participation in student scientific conferences, student work competitions, student scientific societies, circles; activity in student trade unions, student clubs; activity in art groups, student councils organizing mass events; activities in interests associations (sports departments, art groups, studios); activity in pedagogical, labor, construction groups; activities of teaching groups. In terms of content, such activities can be different: cognitive (as well as on the main subjects), artistic and aesthetic, political, sports, labor, socially useful. In her dissertation, Burtseva identifies and substantiates the following potentials of extracurricular activities:

1) Such activities allow students to communicate with different ages, different professions, which meets their communication needs and develops their communication skills; helps to understand life in communication and get acquainted with future professional activity;

2) By engaging in extracurricular activities, students become participants in various small groups, and often these groups become referents for them, ie they can have the most positive impact on the development of personal and professional qualities and the formation of professional orientation;

3) Extracurricular activities allow cadets to choose the content, form, degree, and position of participation, which cannot be realized during the teaching process. This creates conditions for the development of independence, responsibility, activity, and socially significant qualities of each cadet;

4) Extracurricular activities allow cadets to realize their growth potential, as well as strengthen their activity, independence, and sense of responsibility not only for themselves but also for other people;

5) Complements and expands the scope of extracurricular activities, which enriches the social experience of students and has a positive impact on the development of their personality, increases the level of professional knowledge and skills;

6) During extracurricular activities, students' interest in scientific, artistic, social creativity and other activities increases;

7) Extracurricular activities "expand" the scope of the university; provide opportunities for cooperation with public organizations and institutions, which contributes to the development of the social experience of cadets.

\section{The Results of the Study}

In view of the above, we can conclude that extracurricular activities are important. Boritko studied the organization of professional training of future specialists in various forms in the context of the implementation of educational opportunities. It is noted that extracurricular activities have more educational potential than the content of education, as they are mainly characterized by voluntary participation, flexible schedules, and high initiative of students (Belkin, 2000).

The following approaches are very interesting in determining the directions of activity organization ${ }^{1}$ (Lagrone, 2020):

- $\quad$ public practices: to take an active part in public organizations and associations, in the preparation of elections, in the real-life of a university, city, or country;

- $\quad$ self-service: duty at the university, canteen, community service, security in the auditoriums where they are located. Participation of students in the creation and maintenance of their subject-spatial environment in the creation of an educational environment that is the basis for the growth and strengthening of the subjectivity of the future specialist;

- leisure time: rest (removes fatigue and tension, restores physical and mental strength); entertainment (feature film screenings, concerts and theater visits, performances and sports competitions, walks and trips that help to open one's identity are often compensatory in place of monotonous work); 
- holidays (they combine leisure and entertainment); on any holiday (national, religious, political, professional, family, etc.) a person is to some extent free from daily worries, feels uplifted, and has the opportunity to express their feelings openly);

- $\quad$ self-education (aimed at inculcating cultural values in people and, as a rule, not related to vocational training and professional development. Unlike teaching in educational institutions, it does not give any formal right to hold a certain position, to continue education. Participation in excursions, lectures, listening to music, watching scientific and documentary films);

- creativity (expansion of non-professional activities - various arts, technical creativity, various "hobbies" and hobbies);

- Organizational experience in the preparation and holding of various events: holidays and discos dedicated to freshmen. In this case, the organizers of the event can be separate cadets, initiative (creative) groups, academic groups, courses, associations within the interests. It is important that cadets play an organizing role in organizing and conducting such events, and the teaching and technical service structures of the university should help without interfering with their activities (Bashirova, 2020). Recent research on the education and training of future specialists in military universities highlights certain aspects of the organization of extracurricular activities and identifies opportunities for solving the problems of forming competitive graduates.

\section{Discussion of the Results Obtained}

Improving the higher education system, including the training of future officers for our armed forces in the XXI century and raising the teacher-cadet relations to the level of modern requirements in this context is one of the challenges of the time. Although Russian researchers have done extensive research on the problem, they have highlighted the comprehensive, structural, and functional aspects of reform and training in military schools, without touching on improvement. The potential for extracurricular activities in the training of highly qualified specialists for the armed forces in relation to military educational institutions has only recently begun to be explored. In particular, research on the extracurricular activities of cadets is studied outside the educational process, but within the educational institution, which contributes to the development of the individual, the expansion and deepening of social and professional knowledge, the formation of socially important qualities (Burtseva, 2005; Vygotsky, 1983). The author emphasizes the essence of the formation of information competence of cadets in extracurricular activities, expanding their knowledge, developing knowledge and skills in information activities, adequate use of new information technologies in solving certain social and professional tasks, improving their skills and experience of working with information and improving their updating ability understands as. The content of such activities is presented (Ilyasov, 1986), in the following areas: training that significantly expands the existing knowledge and skills of the future officer required for military-professional and daily work; Enlightenment of cadets to acquire new knowledge about search tools, information processing, and transmission, achievements of the information society (information, computer technologies, innovations in the field of the Internet). In this case, various journals, websites, libraries, a series of scientific reports on new inventions of the information society act as means of enlightenment; activities - extracurricular activities conducted by cadets and themselves to help them understand the importance of what they have learned during training and what they have learned during education. Such events include electives, courses, clubs, quizzes, master classes, computer courses, implementation and defense of research and educational projects, training, competitions, etc. performs.

Who studies the formation of a research culture during the extracurricular activities of cadets of military schools Morozova (2002) draws a number of scientifically interesting conclusions on the subject. He states that extracurricular activities are a favorable area for the development of the professional orientation of the individual, as it activates the subjective position of the future specialist by giving the cadet the opportunity to choose different forms of self-affirmation. Stimulates interaction and communication with teachers and peers, provides experience in applying the knowledge gained during teaching, and assists in social and professional development and correction.

In the course of the experimental research, the author found that such an approach to the organization of extracurricular activities increased the cognitive motivation of cadets to $38.7 \%$ in the middle stage and $85.8 \%$ in the final stage; motivation to succeed changed from $6.4 \%$ to $43.5 \%$ at the end of the experiment; The fully-operational component of the activity was $8.1 \%$ at the initial stage, up to $33.9 \%$ at the intermediate level and $62.9 \%$ at the final stage. The number of low-achieving students decreased by $1 / 3$, the average level of students decreased by $7.6 \%$, and the number of high-achieving students doubled. The results of the experimental 
work are generally Confirms Morozova's hypothesis (Morozova, 2009). From the point of view of the formation of the research culture of the cadets, the result is that such content of extracurricular activities is expedient. Based on the analysis of the above research, we would like to define the essence of the concept of "extracurricular activities" in the following context: is any activity that contributes to the deepening and expansion of competence.

As Mishenko rightly points out, the content of out-of-class work in military schools (Morozova, 2002) is a complex and specific socio-pedagogical phenomenon that demonstrates the educational potential of the military community at four levels (interaction of the university, departments, teaching group and individual with others). From the point of view of our research, the above is related to personal activities (teaching-cognition), attitudes (among participants), skills (qualities, knowledge, skills, and habits), military institutions (officer councils, unified leadership, meetings, etc.). Although it is possible to distinguish, the goal is to use the pedagogical potential of each of them. In this case, we mean the following in the concept of potential: 1 . it is a physical quantity that characterizes the field of force at a given point. 2 . The degree of power in any relationship is a set of opportunities and means needed for something in any field (Sitarov, 2008). In other words, the potential of extracurricular activities is its ability to successfully solve specific tasks in a particular field. Its capabilities include information, communication, organizational demonstration, integration.

The information potential of extracurricular activities is realized, firstly, through various forms of teaching the ability to work with information, and secondly, through extensive training of cadets on the curriculum and variants and invariant parts of state educational standards and morals, spiritual, legal, life values.

The organizational potential of extracurricular activities is a pedagogically thought-out use of general organizational forms of activity. It is also divided into training planning (theoretical and practical training, exercises, study of combat equipment), service-planning (practical work on the use of weapons and equipment, park-economy days, regulation days), and non-service (quizzes, competitions, thematic) events, etc.).

During the development and implementation of specific forms of activity, such as firearms, tactical, special-tactical, command, and command-staff exercises, interaction is provided between cadets and students of different courses, teachers (young teachers and those with extensive pedagogical and military experience). Older teachers), officers, and students are expected to inherit. Therefore, the realization of organizational potential is aimed at combining and regulating knowledge, skills, and abilities based on additional opportunities for extracurricular activities, using different options of time regulation, changing the configuration of groups to determine the position of learners in terms of individual contribution (Note 3).

Demonstration potential - demonstration (lat. Demonstration- show), one of the meanings - visual acquaintance with any object or event; do not show it to everyone; to present something demonstratively (Shapar, 1997). In modern didactics, a demonstration is defined as a set of teacher's actions that consist of showing students subjects, processes, events, or a model of them, as well as an explanatory presentation of specific events.

\section{Results and Suggestions}

Based on the above, as a result of our research, we propose three main styles of activity to raise the teacher-trainee relationship to a higher level: 1) preventive style (the teacher actively influences the development of the trainee's personality and follows it); 2) supportive style (the teacher adapts to the development of the trainee's personality - supports the best in the development of his personality); 3) situational style (the teacher only situationally affects the development of the cadet and his personality).

The general conceptual approach to the development of a synthetic model of teacher-trainee interpersonal relationships is as noted above. There are also teachers who share optimistic and pessimistic views on the process of personality development and the combination of demands with respect for the individual (Makarenko).

Currently, the "personality" approach is a strategic task of pedagogical technology in the process of military education. In this approach, the factor that creates the system is clearly stated - the unique personality of the learner.

Issues of development of the cadet's personality are taken in the context of the integrity of his life activity, and the specific conditions of personality development are taken in the context of a certain stage of his development. In this case, it is necessary to take into account the following: development of a unified methodology for the organization of personality development environment (ecological approach to technology and application of biographical method), the professional role of the trainee and the relationship of personality development with the meaning and purpose of human life (anthropological approach), the existence of "spiritual" belief (cultural 
approach), self-expression and self-affirmation in real social life (personalist approach), intensive use of personal potential by cadets to realize the professional role of all life force (individual approach), the realization of human interests and needs in action (activity approach), activity in cadet personality development, creativity, amateurism, freedom, self-education, self-education, etc. (subjective approach), moral bases of humanism of military profession (humanist approach).

We also emphasize the special role of extracurricular activities in raising the credibility and sincerity of teacher-cadet relations in military universities, as well as the following potentials of this activity: information, communication, organization, demonstration, integration. These potentials contribute to the successful solution of specific issues of professional training in the training of military specialists. Our conclusion is that extracurricular activities have a wide range of opportunities to be less regulated, to be more creative, to implement the goal-action-result-reflection algorithm, to perform the function of teaching, directing, and uniting. This area of activity serves to increase the sincerity of teacher-trainee relations, as well as to ensure the interest of students in the subject, to replace methods and forms of understanding, to use the diagnostic nature of the interaction, to eliminate obstacles, fear of making mistakes, to create conditions for success, formation, ensuring corporate culture.

\section{Disclosure Statement}

No potential conflict of interest was reported by the author(s).

\section{Data Availability Statement}

Data sharing is not applicable to this article as no new data were created or analyzed in this study.

\section{References}

Aliyev, H. A. (n/a). The way to independence. Selected ideas. Baku: Azerbaijan University publishing house.

Ananev, B. G. (1968). Man as a subject of knowledge. L.: Leningrad State University.

Babansky, Y. K. (1982). Problems of increasing the effectiveness of pedagogical research. M.: Pedagogika.

Bashirova, G. I. (2018a). The role of extracurricular activities in the formation of responsible attitude to training among cadets., Research papers, 85(6), 41-49. Ministry of education of the AR Institute of education.

Bashirova, G. I. (2018b). Pedagogical cooperation is a prerequisite for optimization relations between teachers and cadets. VII international correspondence scientific specialized conference "International scientific review", pp. 52-63.

Bashirova, G. I. (2018c). Teachers and students of the pedagogical cooperation of foreign literature in the twentieth. VII international correspondence scientific specialized conference "International scientific review".

Bashirova, G. I. (2019a). Formation of an optimal model of pedagogical interaction between teachers and students in the educational process of special universities. Problems of science, 5(44), 33-38.

Bashirova, G. I. (2019b). Forming optimal models, pedagogical models in special incorrect information technology management and course professional development institute in time training processes shopping processes. XI International correspondence scientific specialized conference (Boston, USA. May 16-17, 2019), pp. 15-26.

Bashirova, G. I. (2020a). Socio-pedagogical factors of modernization of humanitarian training of cadets of military-special educational institutions. Science, education and culture, 10(54), 17-22.

Bashirova, G. I. (2020b). Scientific approaches to the organizational and pedagogical substantiation of modernization of humanitarian training of cadets in special military educational institutions. European Science, 7(56), 40-45.

Bashirova, G. I. (2020c). Pedagogical aspects of the organization of humanitarian training of officers in military universities abroad. XXII International scientific review, 12-23.

Belkin, A. S. (2000). Foundations of age-related pedagogy. M.: Academia.

Burtseva, T. A. (2005). Formation of socially significant qualities of a student's personality in the extracurricular activities of the university ( $\mathrm{PhD}$ thesis). Kostroma State University N. A. Nekrasova, Kostroma, Russian Federation.

Filatov, O. K. (1999). Informatization of modern teaching technologies in higher education (PhD thesis). Federal State Budgetary Institution "Russian Academy of Education". Moscow. 
Ilyasov, I. I. (1986). The structure of the learning process. M.: Publishing house of Moscow State University.

Kan-Kalik, V. A. (1987). To the teacher about pedagogical communication: A book for the wearer. M.

Lagrone, J. (2020). Teacher Cadet Program an Important Conduit for Teachers Story.

Morozova, I. S. (2002). Cognitive activity of the individual. Kemerovo: Kuzbassvuzizdat.

Morozova, O. G. (2009). Formation of a research culture among cadets of a military university in extracurricular activities ( $\mathrm{PhD}$ thesis). Kostroma State University N. A. Nekrasova, Kostroma, Russian Federation.

Shapar, B. C. (Ed.). (1997). Dictionary of practical psychologist. M.: Knowledge.

Sitarov, V. A. (2008). Didactics. M: Academy.

Slastenin, V. A. (1998). Dominant activity. M.: Public education.

Vygotsky, L. S. (1984). Collected Works.

Vygotsky, L. S. (1983). Psychology of a teenager. Works. M.: Pedagogy.

Zuckerman, G. A. (1996). From the ability to cooperate to the ability to teach yourself. Psychological Science and Education, 1, 27-43.

\section{Notes}

Note 1. Best practices for high school grow your own teacher programs. July 2019.

Note 2. Careers in Education - Career Technical Education ... (This CTE program is being revised and will not be offered for the 2021/22 school year).

Note 3. Public schools of Edison Township Office of curriculum and instruction. August 24, 2020.

\section{Copyrights}

Copyright for this article is retained by the author(s), with first publication rights granted to the journal.

This is an open-access article distributed under the terms and conditions of the Creative Commons Attribution license (http://creativecommons.org/licenses/by/4.0/). 